\title{
Article \\ Computer Assisted Surgery and 3D Printing in Orthopaedic Oncology: A Lesson Learned by Cranio-Maxillo-Facial Surgery
}

\author{
Giuseppe Bianchi $^{1, *(D)}$, Tommaso Frisoni ${ }^{1}\left(\mathbb{D}\right.$, Benedetta Spazzoli ${ }^{1}$, Alessandra Lucchese ${ }^{2,3,4}$ (D) and \\ Davide Donati $^{1}$ D
}

1 IRCCS Istituto Ortopedico Rizzoli, Clinica Ortopedica III, 40136 Bologna, Italy; tommaso.frisoni@ior.it (T.F.); benedetta.spazzoli@ior.it (B.S.); davide.donati@ior.it (D.D.)

2 Unit of Orthodontics, Division of Dentistry IRCSS Ospedale San Raffaele Scientific Institute, 20132 Milan, Italy; lucchese.alessandra@hsr.it

3 Unit of Orthodontics, School of Dentistry, Vita-Salute San Raffaele University, 20132 Milan, Italy

4 Research Center for Oral Pathology and Implantology, Unit of Dentistry, IRCSS Ospedale San Raffaele, Scientific Institute, 20132 Milan, Italy

* Correspondence: giuseppe.bianchi@ior.it; Tel.: +39-051-6366267

Citation: Bianchi, G.; Frisoni, T.;

Spazzoli, B.; Lucchese, A.; Donati, D. Computer Assisted Surgery and 3D Printing in Orthopaedic Oncology: A Lesson Learned by Cranio-MaxilloFacial Surgery. Appl. Sci. 2021, 11, 8584. https://doi.org/10.3390/ app11188584

Academic Editor: Oleh Andrukhov

Received: 2 August 2021

Accepted: 8 September 2021

Published: 15 September 2021

Publisher's Note: MDPI stays neutral with regard to jurisdictional claims in published maps and institutional affiliations.

Copyright: (c) 2021 by the authors. Licensee MDPI, Basel, Switzerland. This article is an open access article distributed under the terms and conditions of the Creative Commons Attribution (CC BY) license (https:// creativecommons.org/licenses/by/ $4.0 /)$.

\begin{abstract}
Primary bone sarcomas are rare tumors and surgical resection in combination with chemo and radiation therapy is the mainstay of treatment. Some specific anatomical sites still represent a reconstructive challenge due to their complex three-dimensional anatomy. In recent years, patient specific instruments along with 3D printing technology has come to represent innovative techniques in orthopaedic oncology. We retrospectively reviewed 23 patients affected by primary bone sarcoma treated with patient-specific instruments and 3D printing custom made prostheses. At follow up after approximately two years, the infection rate was $26 \%$, mechanical complication rate $13 \%$, and local recurrence rate $13 \%$ (with a five-years implant survival rate of $74 \%$ ). Based on our experience, patient-specific instruments and 3D custom-made prostheses represents a reliable and safe technique for improving the accuracy of resection of primary bone tumour, with a particular use in pelvic surgery ameliorating functional results.
\end{abstract}

Keywords: computer assisted surgery; 3D printing; bone sarcomas

\section{Introduction}

Primary malignant bone tumors are exceptionally rare, accounting for only $0.2 \%$ of all neoplasms with an overall annual incidence rate in Europe of 0.8 per 100,000 people. The incidence rates of specific bone sarcomas are age-related and have a bimodal distribution. Their clinical, radiographic, and histological characteristics are well known and there is consensus on their management (surgery, chemotherapy, and radiotherapy alone or in combination each other) according to national and international treatment protocols in referral centers for bone sarcomas and according to each specific histotype. In localized disease, 5 -yrs overall survival is 65\% for osteosarcoma, $60-75 \%$ for Ewing Sarcoma, and $75-80 \%$ for chondrosarcomas [1].

The role of surgery is unquestionable in any other type of primary bone sarcoma. Over the past twenty years, improvements in prosthetic designs, materials and surgical techniques have guaranteed an excellent implant survival and functional outcome (particularly for sarcomas affecting the appendicular skeleton). Nevertheless, some specific sites of presentation (the pelvis, spine, scapula, periarticular tumors) still represent a challenge either for safe tumor resection or for acceptable functional reconstruction due to their complex three-dimensional anatomy.

The uptake in the use of computer assisted surgery and 3D printing is in response to these factors in a bid to minimise the incidence of inadequate resection margins and improving patients' functional outcome. 
In recent years, "image based" computer assisted surgery (CAS) has been developed along with 3D printing technology and now provides opportunities for personalizing reconstruction with custom-made prostheses [2-5] and improving accuracy in bone cutting using patient-specific instruments (PSI) [6].

Orthopaedic surgery and oral and maxillofacial surgery were among the first specialties to adopt this technology [7-14] and the advent of electron beam melting (EBM) rapid prototyping (RP) techniques have improved the process which directly produces a physical object with a defined structure and shape based on virtual/mathematical model data, ensuring personalized and anatomical reconstructions after bone tumour resection. Rapid prototyping was first used in the late 1990s and was developed to apply the precision and functionality of computer assisted design (CAD) to manufacturing [15]. With this technology, a prototype could be quickly produced and accurately represents the engineers draft $[16,17]$. Furthermore, if changes needed to be made, the engineer could easily digitally work on the draft and print the redesigned part. The EBM is the optimal technology to fabricate metallic components with complex shapes and porous structures and has a pivotal role either in the PSI technology and prosthesis manufacturing.

PSI technology has been used during the last decade in maxillofacial surgery, total knee arthroplasty, hip resurfacing, pedicle screw insertion, pelvic, and long-bones osteotomy. Evaluation tests have shown a high accuracy when compared to standard methods with reduced surgery time [18-25]. A case example is reported in Figure 1.

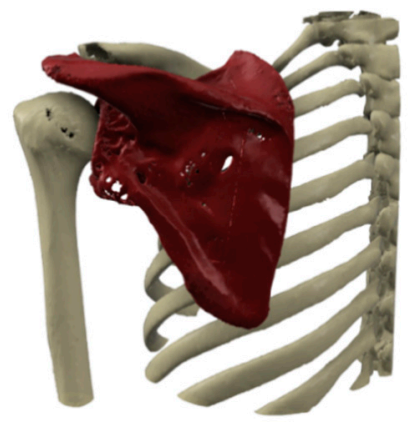

(a)

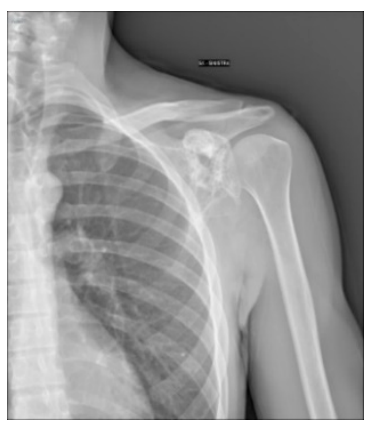

(d)

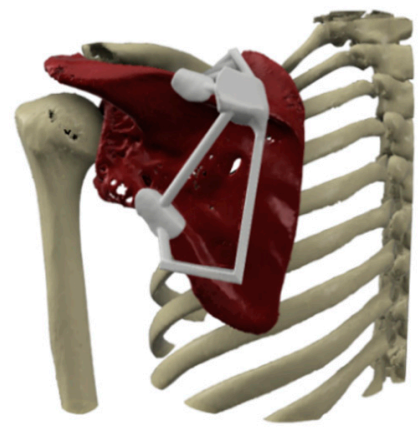

(b)

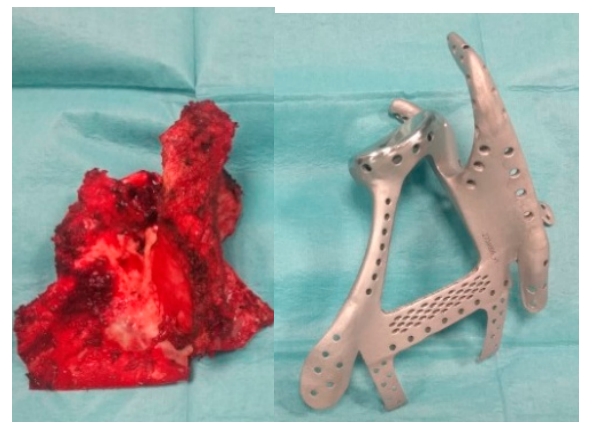

(e)

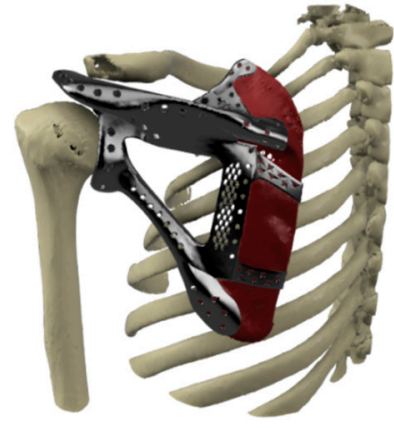

(c)

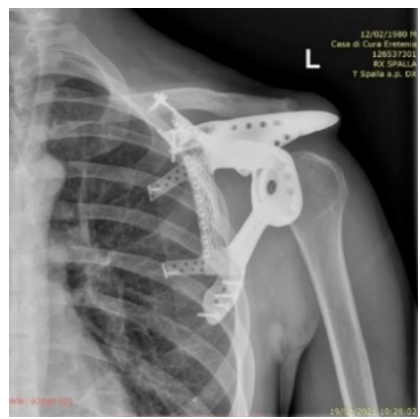

(f)

Figure 1. Case \#10, Male 36 years, low grade osteosarcoma, 3D-virtual model of (a) low grade osteosarcoma of the left glenoid, (b) PSI cutting guide, (c) custom made prosthesis, (d) pre-operative plain X-ray, (e) surgical specimen and custom-made prostheses, and (f) plain X-ray (three years follow up).

The aim of this article is to verify the oncological safety of PSI and 3D custom made prostheses in a selected group of patients affected by primary bone sarcomas. 


\section{Materials and Methods}

From August 2013 to April 2020, 23 patients affected by a primary bone tumour of the pelvis or appendicular skeleton were treated at our Institute with 3D printing custom made prosthesis and PSI technique.

All patients underwent biopsy and histological characterization and complete staging before surgery. Patients affected by malignant tumours received multimodality treatment including surgery, radiotherapy and chemotherapy. Surgery was addressed for limb salvage and to achieve "wide" surgical margins.

Tumour area and surrounding anatomical structures were studied with a CT scan with $1 \mathrm{~mm}$ slices to achieve a representative 3D model, while MRI images were needed for an adequate evaluation of tumour extent within the bone (both medullary and cortically) and in surrounding soft tissues. Patient-specific instruments (PSIs) and implants were designed according to the planned resection strategy.

The fabrication process both for PSIs either for custom implant is in charge of a company which has a specific expertise and industrial workflow for additive manifacturing. Commercial softwares as well as Mimics ${ }^{\circledR}$ (Materialise, Leuven, Belgium) or Invesalius ${ }^{\circledR}$ (freeware) are mostly used for segmentation. PSIs can be molded in nylon or printed in titanium alloy according to the clinical needs and to the know-how of selected companies.

PSIs had bone specific contact surfaces to fit into unique position on the bony structure of the patient based on the shape of the bone acquired by CT scan. PSIs were equipped with flat surfaces and holes to be pinned temporarily on the bone. The final PSI is printed in Nylon or titanium and made sterile for operation.

The virtual custom prosthesis was created defining the better method of fixation according to the part to be reconstructed mirroring the opposite part.

The Ti-6Al-4V implants were fabricated through the deposition of few micron layers of titanium powder melted by electron beams technology (i.e., Electron Beam Melting technique). Implant porosity is widely variable to increase performance and macro-porosity of the body to lighten the implant till micro-porosity at the bone surface contact. These surfaces have pores with an average size of 0.7 millimetres, allowing the host bone to grow directly inside the implant spaces to achieve a stable biological fixation. The prosthesis was provided of tools to allow fixation to the host bone as well as plates or rods, while screws position and lengths were previously planned as well. For articular reconstruction, a polished manufacture or a surface layer (polycaprolactone, PCL or poly-lactic acid, PLA) can be integrated in porous titanium structure.

All analysis was completed using the Statistical Package for Social Science (IBM Corp. Released 2013. IBM SPSS Statistics for Windows, Version 22.0. Armonk, NY: IBM Corp.).

All subjects gave their informed consent for inclusion before they participated in the study.

The study was conducted under Ethical Approval of our Institute (approval code 0024015/2014) and in accordance with the Declaration of Helsinki, all data were retrieved from medical and radiological records of our hospital.

\section{Results}

Among the 23 patients, $5(22 \%)$ were female and $18(78 \%)$ were male. The age ranged from 14 to 76 years old (mean 37). A malignant primary bone tumour was diagnosed in 22 cases $(96 \%)$, while 1 patient suffered a benign tumour (4\%). The pelvic ring was affected in 16 cases $(70 \%)$, whereas in $7(30 \%)$ the appendicular skeleton and extremities were involved. In the group of pelvic ring, the sacro-iliac joint was involved in 3 patients (19\%) and the hip in $13(81 \%)$, requiring sacroiliac joint fusion in the first group and total hip replacement in the second group. Extra pelvic joint involvement was present in two ankles (one distal tibia and one astragalus) and in one shoulder (glenoid). Surgical margins were adequately "wide" in 21 cases (91\%) and "marginal" in $2(9 \%)$ on the soft tissue component. All patients with pelvic tumour (complex surgical anatomy) reported wide margins on the bone. (Table 1). 
Table 1. Demographics, surgical details, complications and follow up of 23 3D/PSI custom implants; * benign tumour ** low-grade malignant tumour.

\begin{tabular}{|c|c|c|c|c|c|c|c|c|c|}
\hline Patient & Gender & Age & Site & $\begin{array}{c}\text { Joint } \\
\text { Involvement }\end{array}$ & Diagnosis & $\begin{array}{l}\text { Surgical } \\
\text { Margins }\end{array}$ & $\begin{array}{l}\text { Revision } \\
\text { Surgery } \\
\text { (Months) }\end{array}$ & $\begin{array}{l}\text { Implant } \\
\text { Removal } \\
\text { (Months) }\end{array}$ & $\begin{array}{c}\text { Patient } \\
\text { Follow Up } \\
\text { (Months) }\end{array}$ \\
\hline 1 & M & 48 & Tibia & & Myxofibrosarcoma & Marginal & Infection (1) & & 14 \\
\hline 2 & M & 76 & Pelvis & Hip & Chondorsarcoma & Wide & Infection (1) & & 2 \\
\hline 3 & M & 18 & Pelvis & Hip & Ewing Sarcoma & Wide & Infection (1) & & 76 \\
\hline 4 & $\mathrm{~F}$ & 23 & Pelvis & Hip & Ewing Sarcoma & Wide & & & 69 \\
\hline 5 & $\mathrm{~F}$ & 26 & Femur & & Osteosarcoma & Wide & & & 11 \\
\hline 6 & M & 22 & Femur & & Ewing Sarcoma & Wide & Infection (1) & & 33 \\
\hline 7 & $\mathrm{~F}$ & 46 & Astragalus & Ankle & Osteosarcoma & Wide & Arthritis (19) & & 19 \\
\hline 8 & M & 56 & Pelvis & Sacro Iliac & Chondorsarcoma & Wide & Infection (1) & Yes & 39 \\
\hline 9 & $\mathrm{~F}$ & 47 & Pelvis & Hip & Chondorsarcoma & Wide & Recurrence (39) & Yes & 44 \\
\hline 10 & M & 40 & Scapula & Shoulder & Osteosarcoma ** & Wide & & & 3 \\
\hline 11 & M & 26 & Pelvis & Sacro Iliac & Ewing Sarcoma & Wide & Screw (1) & & 11 \\
\hline 12 & M & 45 & Tibia & & Osteosarcoma & Wide & Non union (9) & & 18 \\
\hline 13 & M & 55 & Pelvis & Hip & Chondorsarcoma & Wide & Infection (1) & & 1 \\
\hline 14 & $\mathrm{~F}$ & 40 & Pelvis & Hip & Osteoblastoma * & Wide & Recurrence (37) & Yes & 39 \\
\hline 15 & M & 38 & Tibia & Ankle & Chondorsarcoma & Wide & & & 16 \\
\hline 16 & M & 14 & Pelvis & Sacro Iliac & Ewing Sarcoma & Wide & & & 55 \\
\hline 17 & $\mathrm{M}$ & 35 & Pelvis & Hip & Chondorsarcoma & Wide & & & 20 \\
\hline 18 & $\mathrm{M}$ & 28 & Pelvis & Hip & Osteosarcoma & Marginal & & & 48 \\
\hline 19 & M & 45 & Pelvis & Hip & Chondorsarcoma & Wide & & & 33 \\
\hline 20 & M & 26 & Pelvis & Hip & Ewing Sarcoma & Wide & & & 66 \\
\hline 21 & M & 43 & Pelvis & Hip & Osteosarcoma & Wide & & & 8 \\
\hline 22 & M & 26 & Pelvis & Hip & Giant Cell Tumor & Wide & & & 28 \\
\hline 23 & M & 36 & Pelvis & Hip & Chondorsarcoma & Wide & Recurrence (14) & Yes & 62 \\
\hline
\end{tabular}

At a mean follow up of two years (range zero to six), all patients were alive and implants were evaluable for oncological, mechanical, and infective complications.

Six patients (26\%) reported early implant infection $(<1$ months), four after pelvic, one after femur, and one after tibial reconstruction. All patients underwent early surgical debridement associated with antibiotics administration and only one case (sacro iliac joint prostheses) was removed at seven months due to the persistence of infection.

Three patients (13\%) reported implant mechanical complications at a mean follow up of nine months (range 0-19). One patient with astragalus custom made implant developed degenerative arthritis of the ankle and required a new custom-made prosthetic replacement of the distal tibia. One intercalary diaphyseal tibial reconstruction suffered of delayed implant integration and required additional surgery with structural allograft to improve healing process. In one case of sacro iliac joint reconstruction, a S1 root/screw conflict required screw removal.

Three patients (13\%) developed local recurrence at a mean follow up of 30 months (range 13-39). All recurrences occurred after pelvic reconstructions and three underwent hindquarter amputation with prostheses removal.

Overall, three $(13 \%)$ custom prostheses were removed due to complications ( 2 recurrence and 1 infection) at a mean time of 18 months (range 1-39) and with an implant specific survival of $74 \%$ at five years follow up (Figure 2). 


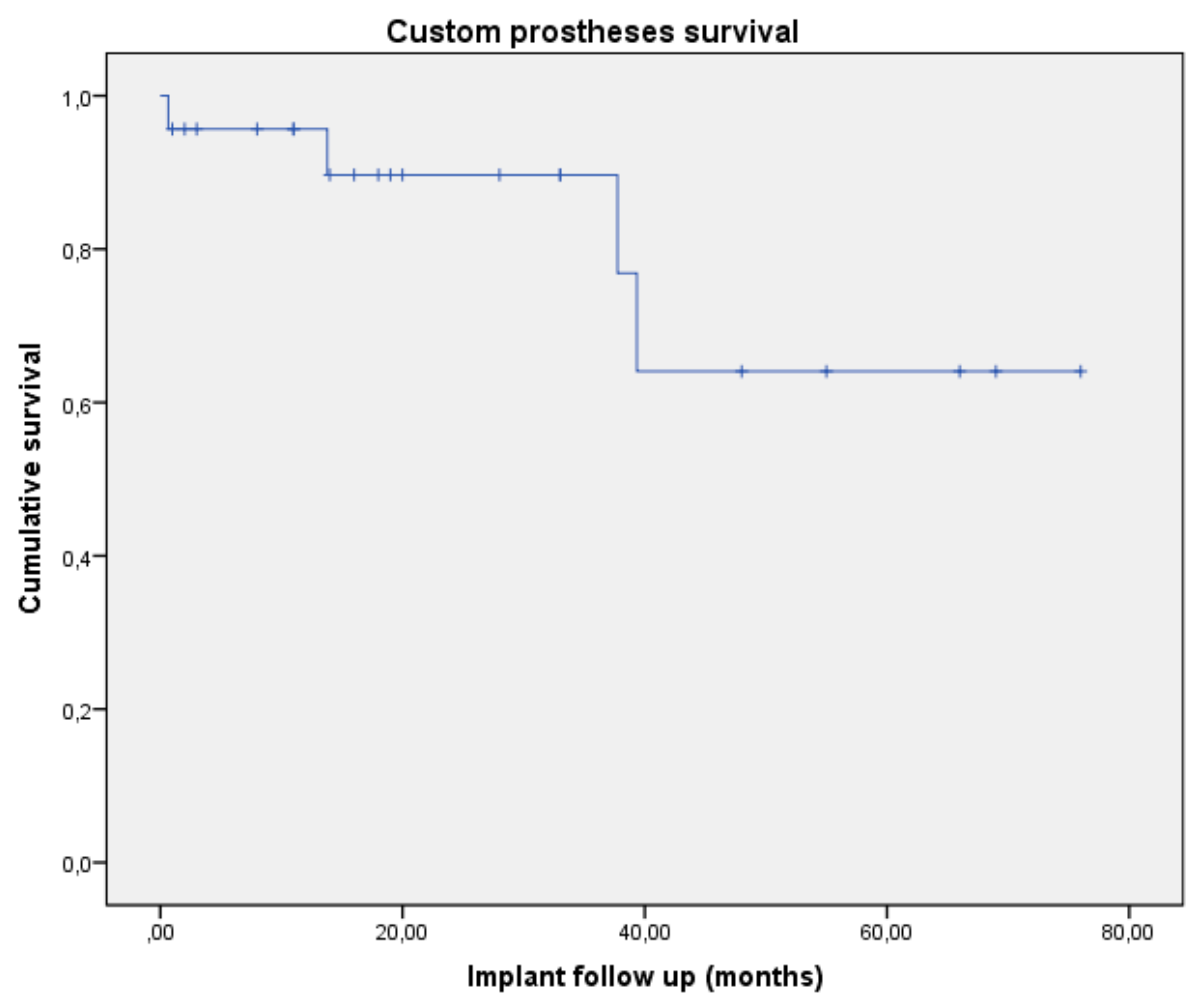

Figure 2. Custom prostheses specific survival. Five years implant specific survival of $64 \%$.

\section{Discussion}

Surgical resection with wide margins is the mainstay of treatment of primary bone sarcomas in a setting of multimodal approach. Modular prostheses still represent the standard of treatment in long bone periarticular reconstructions with complication rates constantly decreasing in modern modular endoprostheses [26]. Prosthetic diaphyseal reconstruction remain a debate with high incidence of failure [27]. Nevertheless, no "off the shelf" implants are available on the market for periarticular reconstruction of complex anatomical site such as hip and shoulder. Bone allograft reconstructions suffer high risk of infection (18-55\%) and mechanical failure (9-22\%) and their role is constantly decreasing and confined to specific indication [28-30].

Rapid prototyping 3D printing and patient specific instruments have been recently described as an emerging alternative technique for "unconventional" reconstructions not effectively supported by prosthetic or bone graft replacement. Liang et al. [31] reported excellent functional results $(75.6 \%)$ and good osteointegration in 35 pelvic custom-made prosthesis after en-bloc tumour resection. Zhang et al. [32] reported excellent functional outcome $(80.3 \%)$ after distal radius resection and custom-made prosthetic replacement. Both of the above-mentioned authors used titanium 3D custom made prostheses manufactured with electron beam melting technology. Other studies encourage the use of this technology also in non-oncological conditions [33-38]. Our series of 23 patients showed a five years implant specific survival of $64 \%$ with low complication rate if considered surgical anatomy and complexity of the patients. Possible advantages in term of management of implant infection emerged from our series, with $75 \%$ of pelvic infection healed after surgical debridement associated with antibiotic administration.

Cernat et al. [39] and Gouin [40] reported 100\% of safe margins in a series of 4 (pelvic) and 11 bone tumors respectively using PSI confirming the possibility to carefully plan bone osteotomy with safety. In our series of 16 pelvic tumours PSI confirmed reliability in term of oncological resection with 100\% adequate (wide) and recurrences not related to PSI. Soft tissues extend of the tumour may also impact on the jig sitting correctly on bony landmarks thereby potentially compromising the resection. Finally, due to the 
delay between planning and jig manufacture there is a possibility for disease progression and therefore a mismatch between planned resection and tumour margins, resulting in intralesional resections [41-43]. Surgeon error is also possible and misplacement of the jigs can again result in intralesional resections.

\section{Conclusions}

Patient-specific instruments and 3D custom-made prostheses represents an innovation that can improve the accuracy of resection of primary bone tumour with a particular use in pelvic surgery ameliorating functional results.

Although burdened by high technology costs, time consuming preoperative planning, and a steep learning curve, further development will make this technology more friendly with potential development towards robotic surgery.

Author Contributions: Conceptualization, G.B., T.F.; methodology, G.B., T.F.; software, B.S., D.D.; validation, G.B., A.L.; formal analysis, T.F., B.S.; investigation, D.D., B.S.; resources, B.S., D.D.; data curation, B.S., D.D.; writing-original draft preparation, G.B., T.F.; writing-review and editing, T.F., D.D., and A.L.; supervision, A.L. All authors have read and agreed to the published version of the manuscript.

Funding: This research received no external funding.

Institutional Review Board Statement: The study was conducted under Ethical Approval of our Institute (approval code 0024015/2014) and in accordance with the Declaration of Helsinki, all data were retrieved from medical and radiological records of our hospital.

Informed Consent Statement: Informed consent was obtained from all subjects involved in the study.

Conflicts of Interest: The authors declare no conflict of interest.

\section{References}

1. Gerrand, C.; Athanasou, N.; Brennan, B. UK guidelines for the management of bone sarcomas. Clin. Sarcoma Res. 2016, 6, 7. [CrossRef] [PubMed]

2. Sun, W.; Li, J.; Li, Q.; Li, G.; Cai, Z. Clinical effectiveness of hemipelvic reconstruction using computer-aided custom-made prostheses after resection of malignant pelvic tumors. J. Arthroplast. 2011, 26, 1508-1513. [CrossRef]

3. Shah, F.A.; Snis, A.; Matic, A.; Thomsen, P.; Palmquist, A. 3D printed Ti6Al4V implant surface promotes bone maturation and retains a higher density of less aged osteocytes at the bone-implant interface. Acta Biomater. 2016, 30, 357-367. [CrossRef]

4. Merema, B.J.; Kraeima, J.; Ten Duis, K.; Wendt, K.W.; Warta, R.; Vos, E. The design, production and clinical application of 3D patient-specific implants with drilling guides for acetabular surgery. Injury 2017, 48, 2540-2547. [CrossRef] [PubMed]

5. Lo Giudice, A.; Ronsivalle, V.; Grippaudo, C.; Lucchese, A.; Muraglie, S.; Lagravère, M.; Isola, G. One step before printingevaluation of imaging software accuracy for 3-dimensional analysis of the mandible: A comparative study using a surface-tosurface matching technique. Materials 2020, 13, 2798. [CrossRef]

6. Cartiaux, O.; Paul, L.; Francq, B.G.; Banse, X.; Docquier, P.L. Improved accuracy with 3D planning and patient-specific instruments during simulated pelvic bone tumor surgery. Ann. Biomed. Eng. 2014, 42, 205-213. [CrossRef] [PubMed]

7. Fan, H.; Fu, J.; Li, X.; Pei, Y.; Li, X.; Pei, G.; Guo, Z. Implantation of customized 3-D printed titanium prosthesis in limb salvage surgery: A case series and review of the literature. World J. Surg. Oncol. 2015, 4, 308. [CrossRef] [PubMed]

8. Sollazzo, V.; Pezzetti, F.; Massari, L.; Palmieri, A.; Brunelli, G.; Zollino, I.; Lucchese, A.; Caruso, G.; Carinci, F. Evaluation of gene expression in MG63 human osteoblastlike cells exposed to tantalum powder by microarray technology. Int. J. Periodontics Restor. Dent. 2011, 31, e17-e28.

9. Rodriguez y Baena, R.; Pastorino, R.; Gherlone, E.F.; Perillo, L.; Lupi, S.M.; Lucchese, A. Histomorphometric evaluation of two different bone substitutes in sinus augmentation procedures: A randomized controlled trial in humans. Int. J. Oral. Maxillofac. Implant. 2017, 32, 188-194. [CrossRef]

10. Zhang, L.H.; Zhang, Y.Z.; Zhang, L.C.; He, C.Q.; Wang, Y.; Tang, P.F. Custom-made locked plating for acetabular fracture: A pilot study in 24 consecutive cases. Orthopedics 2014, 37, e660-e670.

11. Imatani, J.; Ogura, T.; Morito, Y.; Hashizume, H.; Inoue, H. Custom AO small T plate for transcondylar fractures of the distal humerus in the elderly. J. Shoulder Elb. Surg. 2005, 14, 611-615. [CrossRef]

12. Qiao, F.; Li, D.; Jin, Z.; Gao, Y.; Zhou, T.; He, J.; Cheng, L. Application of 3D printed customized external fixator in fracture reduction. Injury 2015, 46, 1150-1155. [CrossRef]

13. Qiao, F.; Li, D.; Jin, Z. A novel combination of computer-assisted reduction technique and three dimensional printed patientspecific external fixator for treatment of tibial fractures. Int. Orthop. 2016, 40, 835-841. [CrossRef] [PubMed] 
14. Iaquinta, M.R.; Mazzoni, E.; Manfrini, M.; D'Agostino, A.; Trevisiol, L.; Nocini, R.; Trombelli, L. Innovative Biomaterials for Bone Regrowth. Int. J. Mol. Sci. 2019, 20, 618. [CrossRef]

15. Kim, G.B.; Lee, S.; Kim, H. Three-Dimensional Printing: Basic Principles and Applications in Medicine and Radiology. Korean J. Radiol. 2016, 17, 182-197. [CrossRef] [PubMed]

16. McGurk, M.; Amis, A.A.; Potamianos, P.; Goodger, N.M. Rapid prototyping techniques for anatomical modelling in medicine. Ann. R. Coll. Surg. Engl. 1997, 79, 169-174. [PubMed]

17. Malik, H.H.; Darwood, A.R.; Shaunak, S. Three dimensional printing in surgery: A review of current surgical applications. J. Surg. Res. 2015, 199, 512-522. [CrossRef] [PubMed]

18. White, D.; Chelule, K.L.; Seedhom, B. Accuracy of MRI vs CT imaging with particular reference to patient specific templates for total knee replacement surgery. Int. J. Med. Robot 2008, 4, 224-231. [CrossRef]

19. Kunz, M.; Rudan, J.F.; Wood, G.C.; Ellis, R.E. Registration stability of physical templates in hip surgery. Stud. Health Technol. Inform. 2011, 163, 283-289.

20. Schkommodau, E.; Decker, N.; Klapper, U.; Birnbaum, S.; Staudte, H.W.; Radermacher, K. Pedicle Screw Implantation Using the DISOS Template System. In Navigation and Robotics in Total Joint and Spine Surgery; Stiehl, J.B., Konermann, W.H., Haaker, R.G., Eds.; Springer: Berlin/Heidelberg, Germany, 2003; pp. 501-505.

21. Dobbe, J.G.; Pre, K.J.; Kloen, P.; Blankevoort, L.; Streekstra, G.J. Computer-assisted and patient-specific 3-D planning and evaluation of a single-cut rotational osteotomy for complex long-bone deformities. Med. Biol. Eng. Comput. 2011, 49, 1363-1370. [CrossRef] [PubMed]

22. Birnbaum, K.; Schkommodau, E.; Decker, N.; Prescher, A.; Klapper, U.; Radermacher, K. Computer assisted orthopedic surgery with individual templates and comparison to conventional operation method. Spine 2001, 26, 365-370. [CrossRef]

23. Donati, D.; Di Bella, C.; Frisoni, T.; Cevolani, L.; DeGroot, H. Alloprosthetic composite is a suitable reconstruction after periacetabular tumor resection. Clin. Orthop. Relat. Res. 2011, 469, 1450-1458. [CrossRef]

24. De Paolis, M.; Biazzo, A.; Romagnoli, C.; Alì, N.; Giannini, S.; Donati, D.M. The use of iliac stem prosthesis for acetabular defects following resections for periacetabular tumors. Sci. World J. 2013, 22, 717031. [CrossRef] [PubMed]

25. Enneking, W.F.; Dunham, W.K. Resection and reconstruction for primary neoplasms involving the innominate bone. J. Bone Jt. Surg. Am. 1978, 60, 731-746. [CrossRef]

26. Smolle, M.A.; Andreou, D.; Tunn, P.U.; Leithner, A. Advances in tumour endoprostheses: A systematic review. EFORT Open Rev. 2019, 4, 445-459. [CrossRef] [PubMed]

27. Ruggieri, P.; Mavrogenis, A.F.; Bianchi, G.; Sakellariou, V.I.; Mercuri, M.; Papagelopoulos, P.J. Outcome of the intramedullary diaphyseal segmental defect fixation system for bone tumors. J. Surg. Oncol. 2011, 104, 83-90. [CrossRef] [PubMed]

28. Traub, F. Biological reconstruction following the resection of malignant bone tumors of the pelvis. Sarcoma 2013, $2013,745360$. [CrossRef] [PubMed]

29. Ozaki, T.; Hillmann, A.; Bettin, D.; Wuisman, P.; Winkelmann, W. High complication rates with pelvic allografts. Experience of 22 sarcoma resections. Acta Orthop. Scand. 1996, 67, 333-338. [CrossRef]

30. Hillmann, A. Tumors of the pelvis: Complications after reconstruction. Arch. Orthop. Trauma Surg. 2003, 123, 340-344. [CrossRef]

31. Liang, H.; Ji, T.; Zhang, Y.; Wang, Y.; Guo, W. Reconstruction with 3D-printed pelvic endoprostheses after resection of a pelvic tumour. Bone Jt. J. 2017, 99, 267-275. [CrossRef]

32. Zhang, S.; Xu, M.T.; Wang, X.Q.; Wang, J.J. Functional outcome of en bloc excision and custom prosthetic replacement for giant cell tumor of the distal radius. J. Orthop. Sci. Off. J. Jpn. Orthop. Assoc. 2015, 20, 1090-1097. [CrossRef]

33. Zhang, Y.D. Effect of 3D printing technology on pelvic fractures: A Meta-analysis. J. Orthop. Traumatol. $2018,31,465-471$.

34. Hung, C.C. Conventional plate fixation method versus pre-operative virtual simulation and three-dimensional printing-assisted contoured plate fixation method in the treatment of anterior pelvic ring fracture. Int. Orthop. 2019, 43, 425-431. [CrossRef]

35. Shon, H.C.; Choi, S.; Yang, J.Y. Three-dimensional printing-assisted surgical technique with limited operative exposure for both-column acetabular fractures. J. Trauma Emerg. Surg. 2018, 24, 369-375.

36. Kim, J.W. Clinical experience with three-dimensional printing techniques in orthopedic trauma. J. Orthop. Sci. Off. J. Jpn. Orthop. Assoc. 2018, 23, 383-388. [CrossRef]

37. Wan, J.; Zhang, C.; Liu, Y.; He, H. Surgical treatment for shepherd's crook deformity in fibrous dysplasia: THERE IS NO BEST, ONLY BETTER. Int. Orthop. 2019, 43, 719-726. [CrossRef] [PubMed]

38. Shi, J. Three dimensional patient-specific printed cutting guides for closing-wedge distal femoral osteotomy. Int. Orthop. 2019, 43, 619-624. [CrossRef]

39. Cernat, E. Patient Specific Instruments for Complex Tumor Resection-Reconstruction Surgery within the Pelvis: A Series of 4 Cases. Chir. Buchar. Rom. 2016, 111, 439-444. [CrossRef]

40. Gouin, F.; Paul, L.; Odri, G.A.; Cartiaux, O. Computer-Assisted Planning and Patient-Specific Instruments for Bone Tumor Resection within the Pelvis: A Series of 11 Patients. Sarcoma 2014, 2014, 842709. [CrossRef] [PubMed]

41. Matarese, G.; Isola, G.; Ramaglia, L.; Dalessandri, D.; Lucchese, A.; Alibrandi, A.; Fabiano, F.; Cordasco, G. Periodontal biotype: Characteristic, prevalence and dimensions related to dental malocclusion. Minerva Stomatol. 2016, 65, 231-238. 
42. Bertossi, D.; Giampaoli, G.; Lucchese, A.; Manuelli, M.; Albanese, M.; Nocini, R.; Nocini, P.F. The skin rejuvenation associated treatment-Fraxel laser, Microbotox, and low G prime hyaluronic acid: Preliminary results. Lasers Med. Sci. 2019, 34, $1449-1455$. [CrossRef] [PubMed]

43. Bianchi, G.; Sambri, A.; Sebastiani, E.; Caldari, E.; Donati, D. Is unicondylar osteoarticular allograft still a viable option for reconstructions around the knee? Knee 2016, 23, 692-697. [CrossRef] [PubMed] 